\title{
FROM THE MERMAID TO ANAL IMPERFORATION: THE SYNDROME OF CAUDAL REGRESSION*
}

BY

\author{
BERNARD DUHAMEL \\ From the Department of Paediatric Surgery, Hôpital de Saint-Denis, France
}

If the mermaid legend evokes more of mythology than of pathology, its origin very probably lies in ancient observations of certain types of human monstrosities.

Human sirens are not as rare as is sometimes thought; I have been able to examine two cases within the past year, and during that time I have been told of several others. I shall talk today of the usual findings and attempt to draw certain wider conclusions.

The fusion of the inferior limbs, the symelia (Fig. 1), which constitutes the characteristic element of the malformation to the observer, is not the only abnormality in these cases (Potter. 1952). The more constant findings in monsters of this general type may be summarized as follows (see Table 1):

1. Flexion and inversion in external rotation of the lower limbs.

2. Anomalies of the lumbar and sacral spine.

3. Imperforate anus.

4. Agenesis of the kidneys and urinary tract.

5. Agenesis of the internal genital organs, with the exception of the gonads.

The visceral anomalies are constant and uniform. It is these anomalies which are incompatible with life, while the symelia is the least grave and the more variable of the malformations presented by the siren. There are even sirenoid monsters in whom

TABLE 1

CHARACTERISTIC ELEMENTS IN SIREN MONSTERS

\begin{tabular}{l|l}
\hline Lower limb anomalies & $\begin{array}{l}\text { Flexion, external rotation; } \\
\text { union (symelia) and often atrophy }\end{array}$ \\
Vertebral anomalies & $\begin{array}{l}\text { Increased in number (epistasis), } \\
\text { or sacral agenesis }\end{array}$ \\
Anorectal agenesis & $\begin{array}{l}\text { Bilateral renal agenesis; } \\
\text { ureteral, vesical and urethral agenesis } \\
\text { Genital anomalies }\end{array}$ \\
\hline
\end{tabular}

* A paper read at a meeting of the British Association of Paediatric Surgeons held in London in July 1960. the lower limbs are flexed and turned into external rotation, but remain independent. These have been called the 'anchipod' type.

It is possible to produce the sirenoid monstrosity in chicken embryos by destruction of the axial portion of the caudal region, between the primitive origins of the pelvic anlage (Wolff, 1948).

If the injury is localized, the lower limbs are not fused, and the anchipodal anomaly is produced. Even more localized lesions may be produced, so that it is possible to spare the lower limbs, the Wolffian system, the vertebral column, and finally have malformations at the cloacal region only.

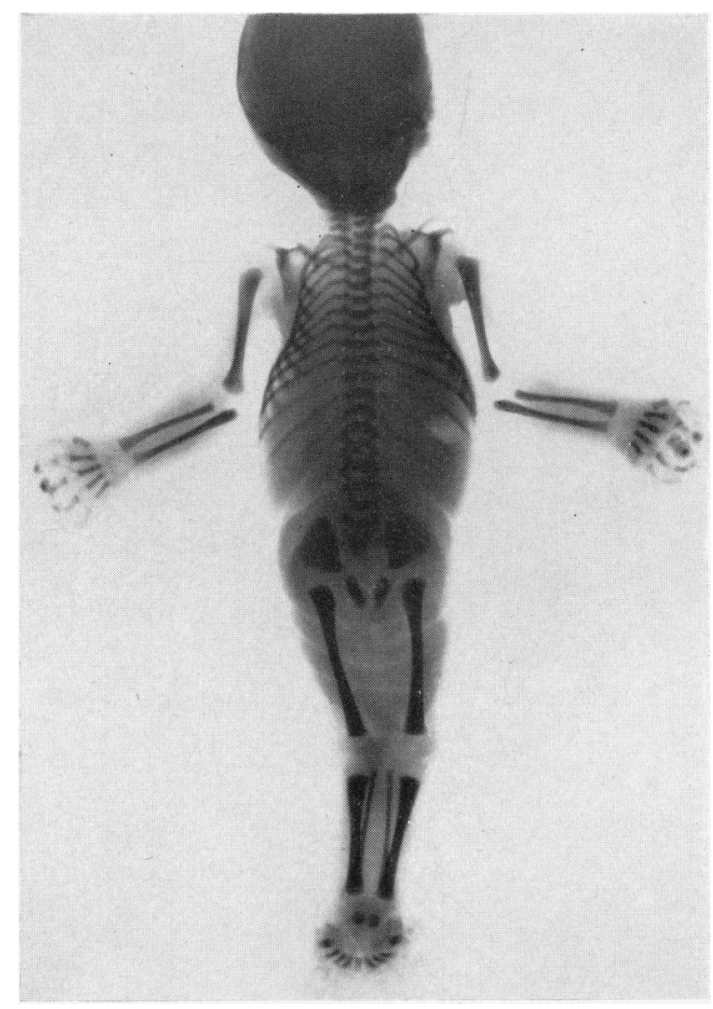

Fig. 1.-A human siren. 


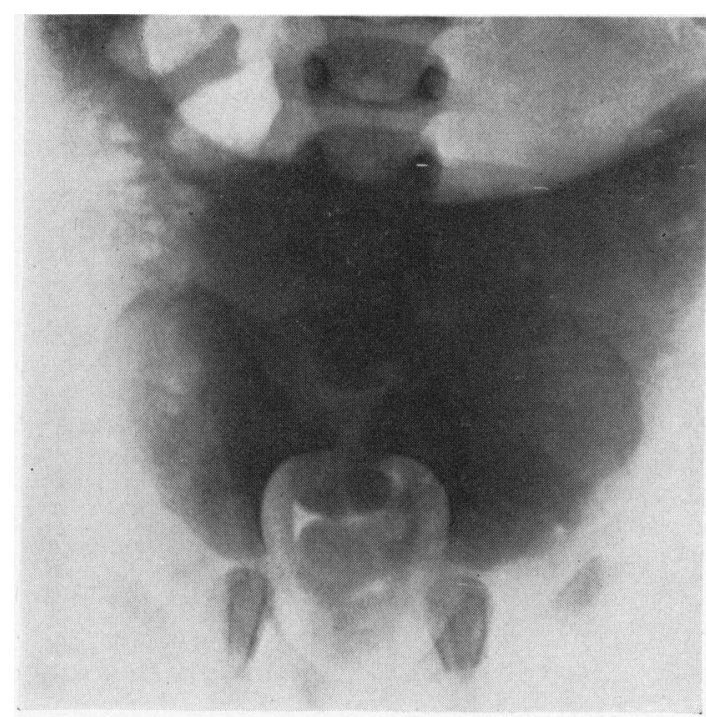

(a)

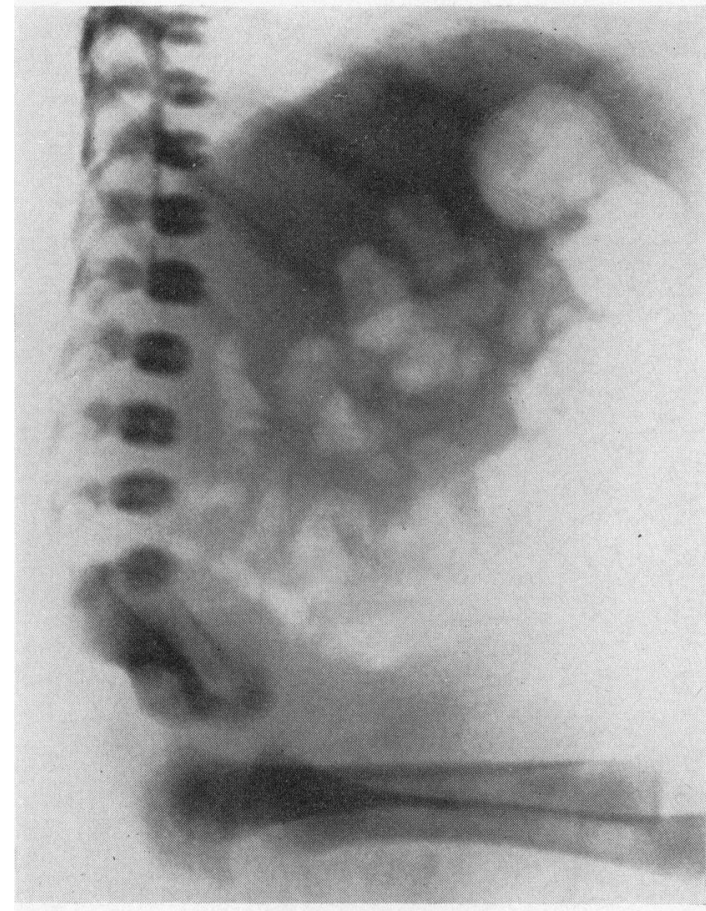

(b)

Fig. 2.-Sacral agenesis: (a) frontal and (b) lateral view.

These experimental findings infer that the siren nonstrosity and malformations of the anal region nay perhaps represent the two extremes of one somprehensive syndrome, that of an embryonal lefect in the formation of the caudal region. I have called this the 'syndrome of caudal regression', and I have attempted to verify its implications in human developmental pathology.

It is well known that anorectal malformations are rarely isolated (Prochiantz, 1957; Parkkulainen, 1957). According to several statistical studies, they are associated with other anomalies in 22 to $72 \%$ of cases. The latter figure is given by Moore and Lawrence (1952), who found, in careful necropsy studies of babies dying with anorectal anomalies, that 33 of 34 cases had other associated anomalies.

Unless one searches carefully and systematically for these anomalies, they may remain unnoticed. Often, however, they play an important part in the gravity of the total disorder, for functional disturbances resulting from these associated malformations may in themselves lead to death.

In 125 cases of anorectal malformations of Ladd types III and IV, there were 76 in which one or more other anomalies were present, an incidence of approximately $60 \%$ (Table 2 ). Since, in the early period, not all of these were studied systematically by radiography and other means, this is probably a minimal figure, and more recent studies have shown an increased proportion.

The most common anomalies in association with anal atresia are those of the vertebral column. I have found them to be present in 50 of the 125 cases. Williams and Nixon (1957) have also commented on their frequency. Included in these abnormalities are sacral agenesis (Fig. 2), vertebral dysmorphia (Figs. 3 and 4), hemivertebra and epistasis (Figs. 5 and 6). These may be found singly, or more often in association with one another (Duhamel, 1959; 1960).

Twenty-four infants were found to have an abnormality of the urinary tract. Of these, the most common was unilateral renal agenesis (Fig. 6). Seventeen showed genital anomalies, amongst which a uterine anomaly was very common (Fig. 7).

Finally, 13 of the cases presented malformation of the inferior limbs. These varied in degree to a considerable extent, and included club foot,

TABLE 2

125 CASES OF ANORECTAL MALFORMATIONS (LADD TYPES 3 AND 4)

Associated Congenital Anomalies in 76 Cases $(60.8 \%)$

\begin{tabular}{|c|c|c|c|c|c|}
\hline \multicolumn{4}{|c|}{ Anomalies } & No. & $\%$ \\
\hline $\begin{array}{l}\text { Vertebral ... } \\
\text { Urinary tract } \\
\text { Genital } \\
\text { Lower limb }\end{array}$ & $\begin{array}{l}\cdots \\
\cdots \\
\cdots\end{array}$ & $\begin{array}{l}\cdots \\
\cdots \\
\cdots\end{array}$ & $\begin{array}{l}\cdots \\
\cdots \\
\cdots\end{array}$ & $\begin{array}{l}50 \\
24 \\
17 \\
13\end{array}$ & $\begin{array}{l}40 \\
19 \cdot 2 \\
13 \cdot 6 \\
10 \cdot 4\end{array}$ \\
\hline Others & . & . & $\cdots$ & 32 & $25 \cdot 6$ \\
\hline
\end{tabular}




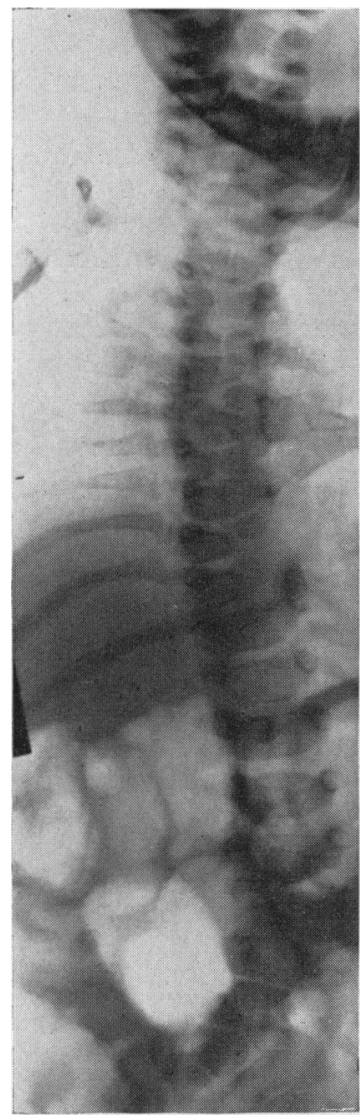

FIG. 3.

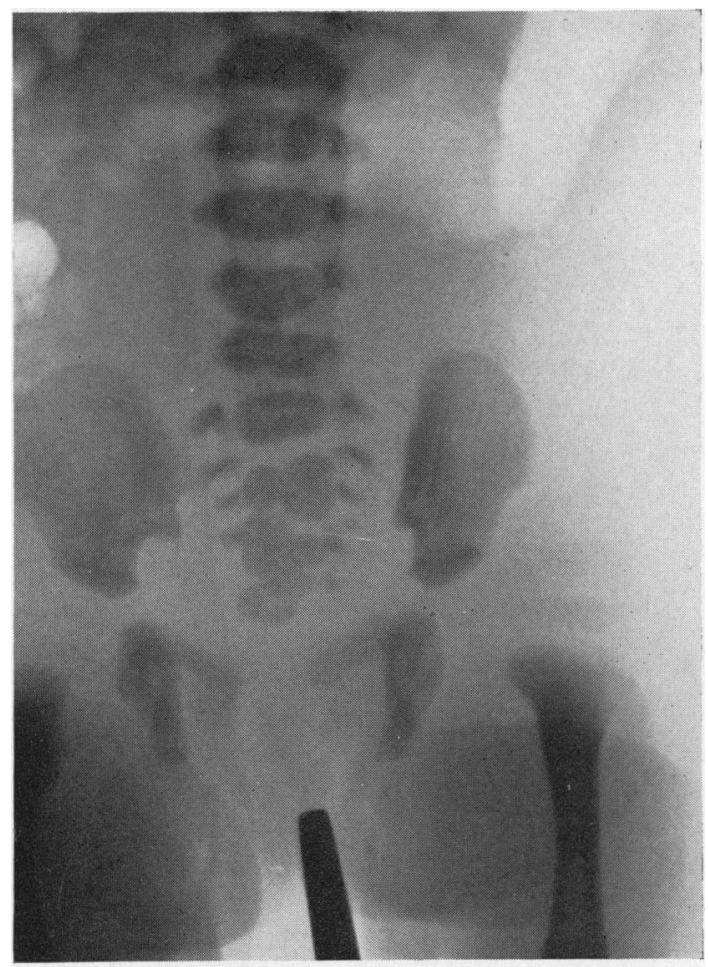

Fig. 3 -Vertebral dysmorphia.

FIG. 4.

FIG. 6.-Epistasis, right renal agenesis, left renal malforma-

tion.

Fig. 5.-Epistasis

A. 12th ribs.

B. Lumbosacral angle.

C. Coccyx.

ळ

जั

윽

FIG. 5.

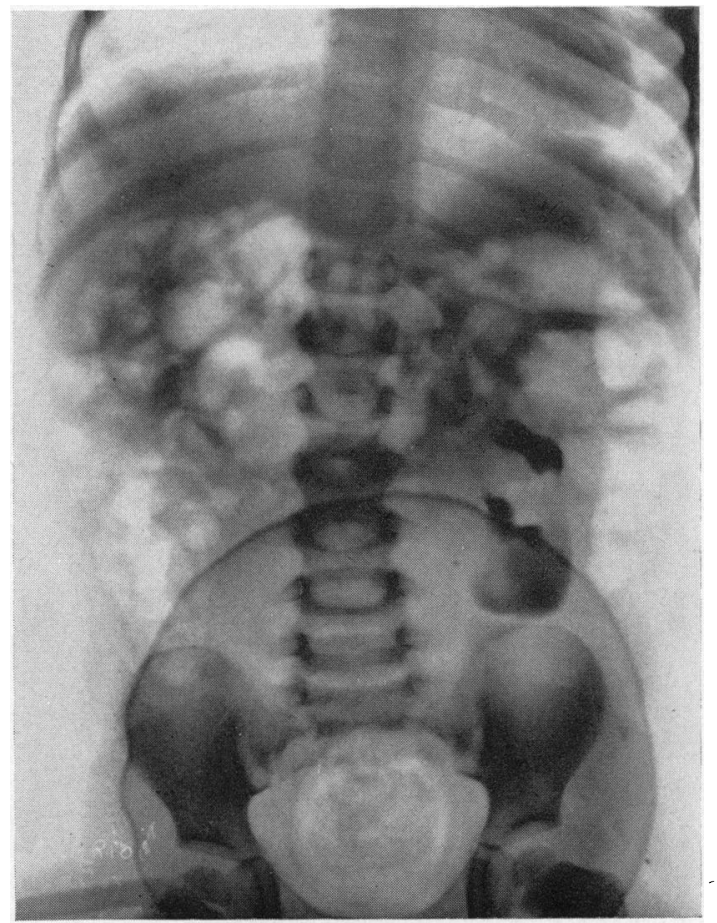

FIG. 6.

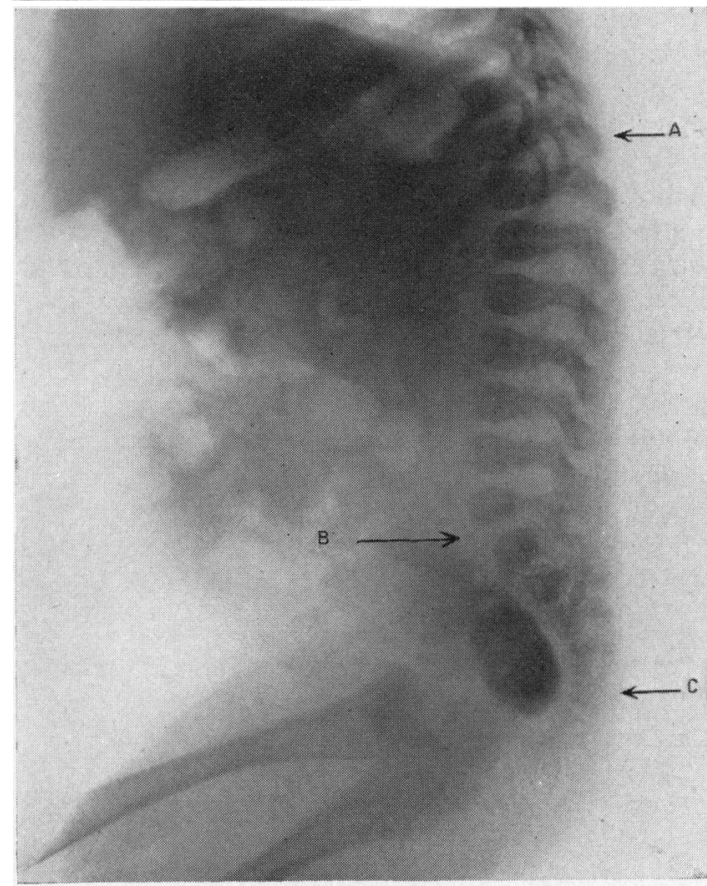




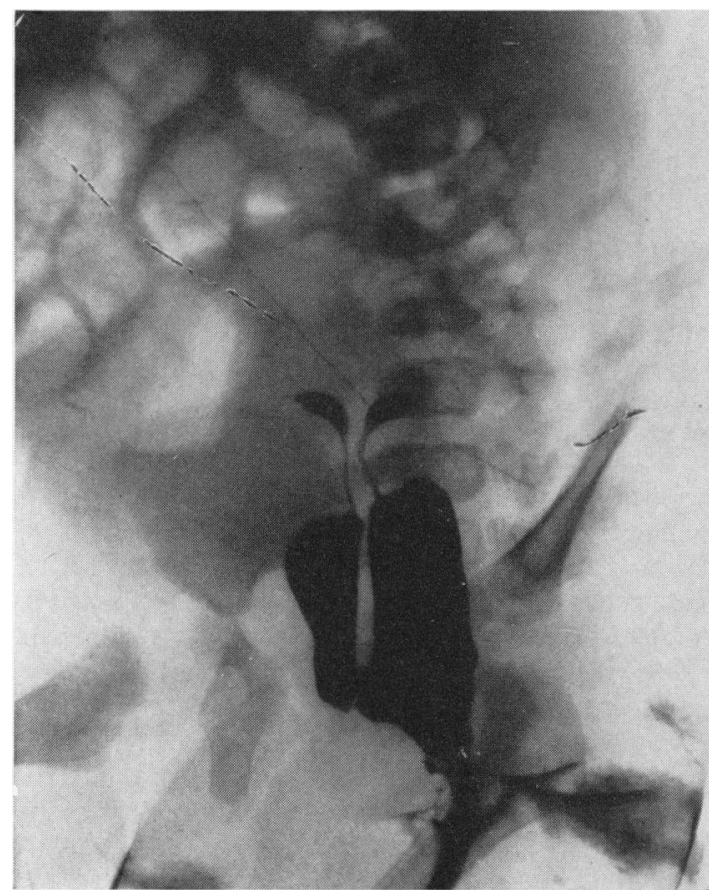

FIG. 7.-Uterine anomaly.

atrophy of the limbs, defective motion of the joints, and in one case flexion and external rotation of the limbs exactly comparable with that found in the anchipodal monster (Fig. 8).

Other anomalies which were found in 32 infants, 21 of whom also had one or more of the malformations listed above, included congenital heart disease, abnormalities of the thumb, and mongolism.

The most frequent malformations associated with anorectal anomalies, therefore, are just those which one finds constantly in the siren, and which can be produced experimentally in the chick embryo by injury to its caudal pole.

In 65 of my 125 cases such malformations were found to be present. In 30 the findings were such that a true syndrome of caudal regression could be considered to exist. Three of the elements listed in the siren monstrosity were present in 17 cases, four were present in 11 and in two all five were found.

The 'syndrome of caudal regression', therefore, shows in variable proportion anomalies of the rectum, of the urinary and genital systems, of the lumbosacral spine, and of the lower limbs.

I have attempted to define this syndrome by means

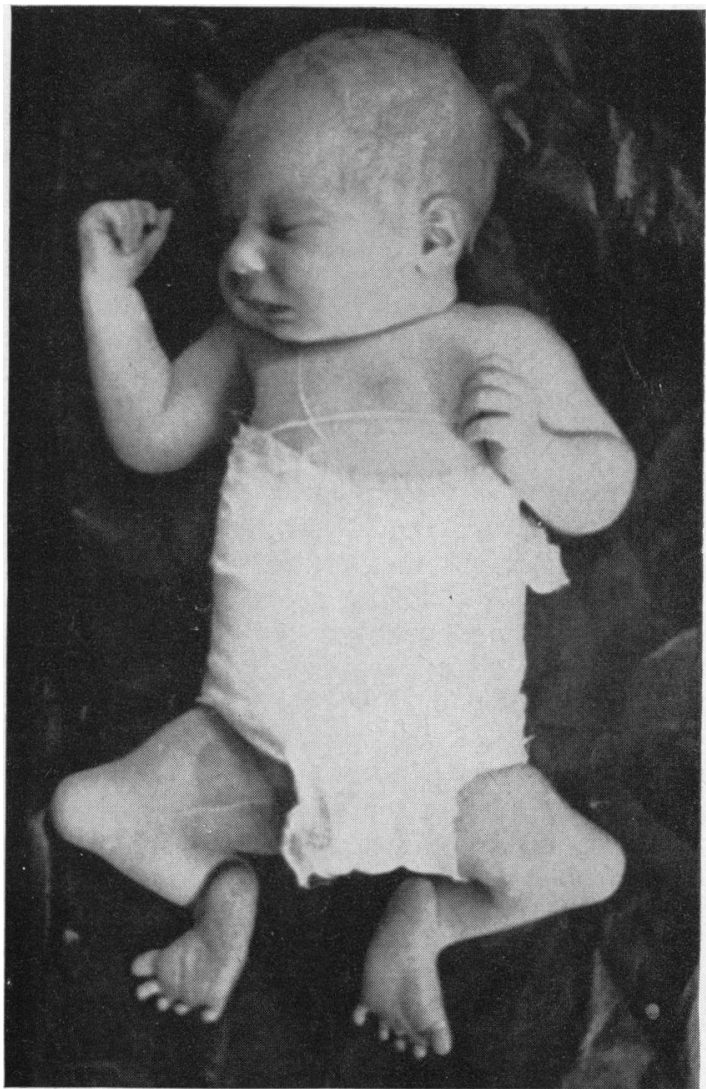

FIG. 8.-A human anchipodal monster.

of comprehensive study of infants with anorectal abnormalities. I believe that similar studies by urologists, gynaecologists, and orthopaedic surgeons, carried out systematically in all cases of this type of anomaly, will show a similarly high percentage of malformations associated in this syndrome.

\section{REFERENCES}

Duhamel, B. (1959). Malformations ano-rectales et anomalies vertébrales. Arch. franc. Pédiat., 16,534.

(1960). L'epistasis et sa signification pathologique. Ann. Chir. inf. (Paris), 1, 99

Moore, T.C. and Lawrence, E. A. (1952). Congenital malformations of the rectum and anus. 1I. Associated anomalies encountered in a series of 120 cases. Surg. Gynec. Obstet., 95, 281.

Parkkulainen, K. V. (1957). Sacrococcygeal and urological anomalies in connection with congenital malformations of anus and rectum. A preliminary report. Ann. Paediat. Fenn., 3, 51 .

Potter, E. L. (1952). Pathology of the Fetus and the Newborn. The Year Book Publishers, Chicago.

Prochiantz, A. (1957). Imperforation anale. Ann. Chir. Paris. 11, c373.

Williams, D. I. and Nixon, H. H. (1957). Agenesis of the sacrum. Surg. Gynec. Obstet., 105, 84.

Wolff, E. (1948). La Science des Monstres. Gallimard, Paris. 